Abstracta Iranica Abstracta Iranica

Revue bibliographique pour le domaine irano-aryen

Volume 34-35-36 | 2017

Comptes rendus des publications de 2011-2013

Pierre Siméon. Hulbuk: Architecture and Material Culture of the Capital of the Banijurids in Central Asia (Ninth-Eleventh centuries)

\title{
Viola Allegranzi
}

\section{OpenEdition}

1 Journals

\section{Édition électronique}

URL : http://journals.openedition.org/abstractairanica/42387

DOI : 10.4000/abstractairanica.42387

ISSN : 1961-960X

Éditeur :

CNRS (UMR 7528 Mondes iraniens et indiens), Éditions de l'IFRI

\section{Référence électronique}

Viola Allegranzi, «Pierre Siméon. Hulbuk: Architecture and Material Culture of the Capital of the Banijurids in Central Asia (Ninth-Eleventh centuries) », Abstracta Iranica [En ligne], Volume 34-35-36 | 2017,

document 3, mis en ligne le 30 juillet 2017, consulté le 26 septembre 2020. URL : http://

journals.openedition.org/abstractairanica/42387 ; DOI : https://doi.org/10.4000/abstractairanica 42387

Ce document a été généré automatiquement le 26 septembre 2020.

Tous droits réservés 


\title{
Pierre Siméon. Hulbuk: Architecture and Material Culture of the Capital of the Banijurids in Central Asia (Ninth- Eleventh centuries)
}

\author{
Viola Allegranzi
}

\section{RÉFÉRENCE}

Pierre Siméon. « Hulbuk: Architecture and Material Culture of the Capital of the Banijurids in Central Asia (Ninth-Eleventh centuries) ». Muqarnas, 29, 2012, p. 385-421.

1 L'article propose une vue d'ensemble sur le site archéologique de Hulbuk, situé dans le Khuttal historique (Tadjikistan actuel), qui a fait l'objet de nombreuses campagnes de fouilles russes et tadjiques à partir des années 1950. L'A. esquisse d'abord le cadre historique et géographique, pour décrire ensuite les structures mises au jour dans le šahrestān et dans la citadelle, noyau principal du site. Les différents secteurs sont présentés selon l'historique des enquêtes archéologiques ; l'A. propose néanmoins une chronologie basée sur le recoupement des données matérielles et historiques connues. Il suggère en particulier que des expéditions punitives lancées par les Samanides (948) et par les Seldjoukides (1064) aient marqué la fin des deux phases d'occupation principales de la citadelle. Au fil de l'étude, sont évoqués les nombreux fragments de peintures murales et de décor architectural en stuc et en brique cuite, ainsi que certains objets de luxe provenant du site. La variété des matériaux et la finesse de leurs décors - géométriques et végétaux, épigraphiques, zoomorphes et anthropomorphes démontrent que les résidences princières de Hulbuk n'avaient rien à envier aux autres sites connus de la région. L'article est enrichi de vingt-cinq illustrations en noir et blanc et en couleur (dont certaines comportant plusieurs images). La plupart consistent en des plans et reconstitutions graphiques tirés des publications précédentes ; plusieurs photos réalisées par l'auteur complètent enfin l'iconographie de cette synthèse, 
précieuse pour les archéologues et historiens de l'art, sur un joyau de l'Asie centrale pré-mongole.

\section{AUTEURS}

VIOLA ALLEGRANZI

Université Sorbonne Nouvelle - Paris 3 et Università degli studi di Napoli « L'Orientale » 